\title{
Diversidade de bactérias diazotróficas endofíticas dos gêneros Herbaspirillum e Burkholderia na cultura do arroz inundado
}

\author{
Luciana da Silva Rodrigues ${ }^{(1)}$, Vera Lucia Divan Baldani(2), Veronica Massena Reis( ${ }^{(2)}$ e José Ivo Baldani(2)
}

(1)Universidade Federal Rural do Rio de Janeiro, Instituto de Agronomia, BR 465, Km 7, CEP 23890-000 Seropédica, RJ. (2)Embrapa Agrobiologia, BR 465, Km 7, CEP 23890-000 Seropédica, RJ. E-mail: vera@cnpab.embrapa.br, veronica@cnpab.embrapa.br, ibaldani@cnpab.embrapa.br

\begin{abstract}
Resumo - O objetivo deste trabalho foi avaliar a diversidade de bactérias diazotróficas endofíticas, dos gêneros Herbaspirillum e Burkholderia, em duas variedades de arroz, consideradas de alta (IR 42) e baixa (IAC 4440) eficiência de fixação biológica de nitrogênio. Foram realizados dois experimentos em casa de vegetação, em vasos com dois tipos de solos, provenientes dos Estados de Goiás e do Rio de Janeiro. Foi feita a contagem do número de bactérias e o isolamento em diferentes partes e estágios de desenvolvimento das plantas, mediante o uso de meios de cultivo JNFb e JMV. Os isolados bacterianos foram caracterizados a partir de aspectos morfológicos das colônias, com o crescimento em meios de cultivo, e de testes fisiológicos (uso de fontes de carbono e atividade de redução de acetileno). A contagem revelou grande número de bactérias diazotróficas ( $10^{6}$ células $\mathrm{g}^{-1}$ matéria fresca), presentes em ambas as variedades de arroz, principalmente nas amostras radiculares. Os dados, obtidos na matriz de similaridade, mostram a presença de representantes da espécie Herbaspirillum seropedicae, bem como a diversidade entre isolados pertencentes ao gênero Burkholderia.
\end{abstract}

Termos para indexação: fixação biológica de nitrogênio, filogenia, interação planta-bactéria.

\section{Diversity of endophytic diazotrophic bacteria of the genus Herbaspirillum and Burkholderia in wetland rice}

\begin{abstract}
The objective of this work was to evaluate the diversity of endophytic diazotrophic bacteria of the genera Herbaspirillum and Burkholderia, in two rice varieties, considered of high (IR 42) and low (IAC 4440) contribution on BNF. Two experiments were conducted in greenhouse conditions, in order to study the association of endophytic diazotrophic bacteria with wetland rice varieties, which were planted in two types of soil: one from Rio de Janeiro State and another from Goiás State, Brazil. Bacterial population (in different parts) and physiological stages of the plants were evaluated, followed by the both genera strains isolation using culture media. The isolated bacteria were characterized based on morphological and physiological aspects. High bacterial counts were detected $\left(10^{6}\right.$ cells $\mathrm{g}^{-1}$ fresh weight), especially in root samples of both rice varieties. The majority of the isolates were used for characterization, and the data obtained from the similarity matrix showed the presence of isolates belonging to Herbaspirillum seropedicae, while other isolates were clustered into the Burkholderia genus.
\end{abstract}

Index terms: biological nitrogen fixation, phylogeny, plant-bacteria interaction.

\section{Introdução}

Diversos estudos têm mostrado que alguns genótipos de arroz cultivados em condições inundadas podem obter parte do $\mathrm{N}$ necessário ao seu desenvolvimento pelo processo de fixação biológica de nitrogênio (FBN) (Ladha et al., 1987). No Brasil, experimentos conduzidos para avaliar o potencial de FBN em diferentes genótipos de arroz, pela técnica de diluição isotópica de ${ }^{15} \mathrm{~N}$, mostraram que o genótipo IR 42 obteve alta contribuição da
FBN, enquanto o IAC 4440, baixa contribuição (Campos, 1999).

As bactérias que habitam o interior do tecido vegetal podem contribuir de forma mais efetiva para a FBN, já que a troca se faz de forma direta, e há menos competição por fontes de carbono, pois nem todos os microrganismos são capazes de penetrar no tecido vegetal (Baldani et al., 1997). Várias bactérias diazotróficas endofíticas, representantes dos gêneros Azoarcus, Azospirillum, Burkholderia e Herbaspirillum, foram 
identificadas em associação com variedades de arroz, em diferentes países. Entretanto, pouco se sabe a respeito da diversidade da população desses gêneros, nessa cultura.

Stoltzfus et al. (1997) constataram uma grande diversidade de bactérias endofíticas em arroz, porém somente $10 \%$ dessas foram caracterizadas como diazotróficas. Estudos moleculares, que utilizaram como marcador o gene nifH, mostraram a ocorrência de oito novos tipos de bactérias diazotróficas presentes na superfície ou no interior da raiz, em relação à rizosfera do arroz (Ueda et al., 1995). A caracterização filogenética de 23 seqüências do gene nifH, obtido a partir da amplificação do DNA extraído diretamente das raízes de arroz, indicou a existência de diversidade de bactérias diazotróficas presentes nessa cultura (Elbeltagy et al., 2001).

A diversidade de bactérias diazotróficas endofíticas, em diferentes genótipos de arroz, varia nos estágios de desenvolvimento e partes da planta. Barraquio et al. (1997), ao estudar as variedades de arroz irrigado, observaram que o número de bactérias diazotróficas endofíticas, em raízes e colmos, variou nos diferentes estágios de desenvolvimento, tendo atingido máximo no florescimento. Segundo esses autores, possivelmente o colmo é um nicho mais sustentável, para endofíticas fixadoras, do que a raiz, por ser, aparentemente, um ambiente menos concorrido por fotossintatos. Engerlhard et al. (2000) constataram que a diversidade de estirpes de Azoarcus foi significativamente menor, em espécies de arroz selvagem, do que em variedades melhoradas geneticamente. Esses resultados sugerem que a diversidade de bactérias diazotróficas endofíticas parece estar condicionada à própria vegetação.

A avaliação da diversidade de bactérias diazotróficas presentes nos tecidos, nos diferentes estágios de desenvolvimento da planta, pode ajudar a compreender o papel desses microrganismos em seu habitat natural.

O objetivo deste trabalho foi avaliar a ocorrência e a diversidade de bactérias diazotróficas endofíticas, associadas a duas variedades de arroz, de alto e baixo potencial de contribuição da FBN, cultivadas em dois tipos de solos, sob condição de inundação.

\section{Material e Métodos}

As variedades de arroz IR 42 (International Rice Research Institute, Filipinas) e IAC 4440 (Instituto Agronômico, Campinas, SP) foram selecionadas, com base na eficiência contrastante da contribuição do sistema de fixação biológica de nitrogênio (FBN), caracterizadas como de alto e baixo potencial da FBN, respectivamente (Campos, 1999).

Antes do plantio, as sementes foram desinfestadas, para que a microbiota associada à planta correspondesse apenas àquela presente no solo (Baldani et al., 2000). A semeadura deu-se depois da pré-germinação das sementes, em placas com ágar-água $1 \%$, por dois dias a $30^{\circ} \mathrm{C}$. Apenas as sementes livres de contaminantes microbianos foram plantadas. Foram usados como tratamentos dois solos hidromórficos, um proveniente do Estado de Goiás e um do Rio de Janeiro, com histórico de cultivo com arroz por, pelo menos, dez anos. A análise granulométrica mostrou que o solo do Rio de Janeiro possui textura argilosa, com $42 \%$ de argila, $37 \%$ de areia e $20 \%$ de silte. O solo de Goiás foi classificado como argilo-limoso com 45\% de argila, 20\% de areia e 34\% de silte. O solo do Rio de Janeiro apresentou $\mathrm{pH} 5$, $4 \mathrm{mg} \mathrm{dm}^{-3}$ de fósforo e $25 \mathrm{mg} \mathrm{dm}^{-3}$ de potássio. O solo de Goiás tinha o mesmo $\mathrm{pH}, 41 \mathrm{mg} \mathrm{dm}^{-3}$ de fósforo e $45 \mathrm{mg} \mathrm{dm}^{-3}$ de potássio.

Foram implantados dois experimentos (setembro de 2000 e abril de 2001) em casa de vegetação, na Embrapa Agrobiologia. Quando necessária, foi feita a correção dos nutrientes $\mathrm{P}, \mathrm{K}$, Zn e calagem. A primeira dose de $\mathrm{N}$ foi aplicada 68 dias depois do plantio (DAP) e correspondeu a $10 \mathrm{~kg} \mathrm{ha}^{-1}$ de $\mathrm{N}\left[\left(\mathrm{NH}_{4}\right)_{2} \mathrm{SO}_{4}\right]$, em ambos os solos (experimento 1). No segundo experimento, a aplicação foi feita aos 48 e 76 DAP, tendo-se aplicado $20 \mathrm{~kg} \mathrm{ha}^{-1}$ de $\mathrm{N}$ na forma de $\left(\mathrm{NH}_{4}\right)_{2} \mathrm{SO}_{4}$. Foram usados vasos com $3,5 \mathrm{~kg}$ de solo sob inundação e mantidos ao ar livre. Os tratamentos foram dispostos em delineamento experimental em blocos ao acaso, com quatro repetições em fatorial 2x2x4, e constituídos por duas variedades de arroz (IR 42 e IAC 4440), dois tipos de solos e quatro épocas: fase vegetativa, $52 \mathrm{DAP}$; florescimento, 100 DAP; enchimento do grão, 123 DAP; e maturação completa dos grãos, 194 DAP.

As amostras compostas foram coletadas em cada estágio de desenvolvimento, das raízes (1/3 superior) e parte aérea (1/3 inferior) das plantas de cada tratamento. Parte dessa amostra (10 g) foi submetida à desinfestação superficial com cloramina T 1\%, por 5 minutos (Döbereiner et al., 1995), e a outra parte (10 g) foi lavada em água corrente. As amostras da parte aérea (10 g) foram desinfestadas superficialmente, com álcool $70 \%$. As amostras foram maceradas em liquidificador, em solução salina, diluídas e inseridas nos meios de 
cultivo semi-sólido, sem $\mathrm{N}$, e semi-específicos para cada gênero: JNFb para Herbaspirillum (Döbereiner et al., 1995) e JMV para Burkholderia (Baldani et al., 2000). Em seguida, as culturas foram incubadas a $30^{\circ} \mathrm{C}$, por um período de cinco a dez dias, para a avaliação da formação de película característica na superfície do meio. A contagem da população bacteriana foi determinada pela técnica do número mais provável (NMP), utilizando-se a Tabela de McCrady para três repetições (Döbereiner et al., 1995).

As culturas que apresentaram o crescimento na forma de película característica, em ambos os meios de cultivo, foram utilizadas no isolamento e purificação das bactérias diazotróficas (Döbereiner et al., 1995; Baldani et al., 2000).

Os isolados obtidos foram visualizados em microscópio ótico de contraste de fase, para a caracterização da morfologia e motilidade celular, de acordo com os dados de descrição das espécies. A morfologia das colônias foi observada em meios sólidos: JNFb, acrescido de três vezes a dose do indicador azul de bromotimol, para o gênero Herbaspirillum; e JMV e BAC para Burkholderia, depois do crescimento por sete dias a $30^{\circ} \mathrm{C}$ (Estrada de Los Santos et al., 2001).

A caracterização fisiológica, baseada na atividade da nitrogenase, foi avaliada pela técnica de atividade de redução de acetileno (ARA) dos isolados obtidos, pela inoculação de uma colônia no meio semi-sólido JNFb e JMV. A incubação foi a $30^{\circ} \mathrm{C}$, por 48 e 72 horas, para os isolados de Herbaspirillum, e por seis e oito dias, para os isolados de Burkholderia. Depois da formação da película, os frascos foram fechados com rolhas de borracha do tipo suba-seal estéreis, e com uma seringa foi injetado $1 \mathrm{~mL}$ do gás acetileno (10\% da sua fase gasosa). As culturas submetidas ao acetileno foram incubadas por uma hora a $30^{\circ} \mathrm{C}$, sem agitação e, posteriormente, $0,5 \mathrm{~mL}$ da fase gasosa foi injetada no cromatógrafo de gás, com ionização de chama, marca Perkin Elmer modelo F11, utilizando-se uma coluna Poropak $\mathrm{N}$ de $50 \mathrm{~cm}$, a $40^{\circ} \mathrm{C}$, onde foi realizada a leitura do etileno formado pela redução do acetileno.

A caracterização fisiológica baseada no uso de fontes de carbono, para os isolados do gênero Burkholderia, foi avaliada pelo kit Biolog. Foram utilizados 22 isolados, obtidos no meio JMV, além de oito estirpes representantes de espécies deste gênero utilizadas como comparação. Esses isolados foram cultivados em meio líquido $\mathrm{JMV}$ por 24 horas, a $30^{\circ} \mathrm{C}$, sob agitação a
$150 \mathrm{rpm}$, riscados duas vezes consecutivas, em meio ágar nutriente, $\mathrm{pH} 5,2$, e incubados por 48 horas a $30^{\circ} \mathrm{C}$. A avaliação do potencial redutor dos isolados, em relação às fontes de carbono, foi realizada segundo Biolog (1999).

Os isolados com características do gênero Herbaspirillum foram inoculados em $5 \mathrm{~mL}$ de meio semi-sólido JNFb, sem ácido málico, pH 6, e acrescido de $\mathrm{N}$-acetilglucosamina (NA), ou meso-eritritol (ME), ou ácido adípico (AA), ou mio-inositol (MI). As fontes de carbono AA e MI foram testadas com e sem $\mathrm{N}$ mineral $\left(\mathrm{NH}_{4} \mathrm{Cl}\right.$ a $\left.0,1 \%\right)$, e as fontes $\mathrm{ME}$ com $\mathrm{N}$ e NA sem N. Todas as fontes foram preparadas em tampão fosfato de potássio $3 \mathrm{mM} \mathrm{pH} \mathrm{6,} \mathrm{esterilizadas} \mathrm{por}$ filtragem em membrana Millipore de 0,2 $\mu \mathrm{m}$, e adicionadas ao meio para obter a concentração final de $5 \mathrm{~g} \mathrm{~L}^{-1}$. A avaliação do crescimento foi feita pela observação da formação de película à superfície. Posteriormente, foi feita uma repicagem para outro frasco com o mesmo meio de cultivo. Este procedimento foi repetido duas vezes, para se confirmar a capacidade dos isolados de usar essas fontes de carbono.

Uma matriz binária foi construída a partir dos dados obtidos, com o uso das diferentes fontes de $\mathrm{C}$ em meio semi-sólido e pelo kit Biolog, e valores de um e zero foram atribuídos para indicar o uso ou não de determinada fonte de carbono. Os resultados de semelhanças foram estimados pelo coeficiente Simple Matching (SM) (Rohlf, 1993) e pelo método das médias das distâncias UPGMA, tendo sido representados, graficamente, por um dendrograma (NTSYS-pc, versão 1.8, Exceter software, Setauket, NY).

\section{Resultados e Discussão}

A população de bactérias diazotróficas endofíticas do gênero Herbaspirillum, cultivadas em meio de cultivo JNFb semi-seletivo, foi menor durante o enchimento de grãos do que nos demais estágios de desenvolvimento para as duas variedades de arroz (experimento 1 ), porém este comportamento não se repetiu no experimento 2 (Figura 1). Resultado semelhante foi observado para as bactérias cultivadas em meio de cultivo JMV - semiespecífico para o gênero Burkholderia - nos dois experimentos (Figura 2). Tanto o manejo dos solos, como a época de plantio e as condições experimentais podem ter influenciado o comportamento diferenciado das populações bacterianas, presentes nas variedades de arroz. De maneira geral, as variedades de arroz 
mostraram tendência de maior colonização por bactérias diazotróficas endofiticas, quando cultivadas em solo de Goiás (Figuras 1 e 2).

No primeiro experimento, foram obtidos 261 isolados, dos quais $63 \%$ foram classificados como similares aos do gênero Burkholderia e 34\% similares aos de Herbaspirillum (Tabela 1). Não foram obtidos isolados com características semelhantes ao Herbaspirillum na variedade IAC 4440 e cultivada no solo de Goiás. A maioria dos isolados foi oriunda de amostras radiculares, principalmente da raiz lavada. Do total de isolados, 51\% foram obtidos da variedade IAC 4440 e $49 \%$ da IR 42, e o número de isolados obtidos nos dois solos foi praticamente o mesmo da variedade IAC 4440. A variedade IR 42 apresentou um maior número de isolados quando cultivada no solo de Goiás, confirmando, assim, os dados populacionais. Portanto, o solo, assim como a variedade de arroz, pode ter influenciado a população das bactérias diazotróficas presentes nos tecidos. Azevedo (1998) constatou que o genótipo de arroz pode influenciar a diversidade populacional de Azospirillum amazonense, no entanto, quando o arroz foi cultivado no Planossolo série Itaguaí, os efeitos discriminatórios ocorreram principalmente nos isolados do interior radicular.

No segundo experimento, foram obtidos 165 isolados, dos quais cerca de $76 \%$ foram de Burkholderia, 18\% de Herbaspirillum e $6 \%$ de bactérias que formavam colônias de coloração amarela (Tabela 1). O maior número de isolados (cerca de 61\%) foi obtido da variedade IR 42, destacando-se os das bactérias originárias do solo de Goiás. Não houve diferença entre as variedades, quanto ao número de isolados, porém houve influência do tipo de solo para a variedade IR 42. No final

Experimento 1
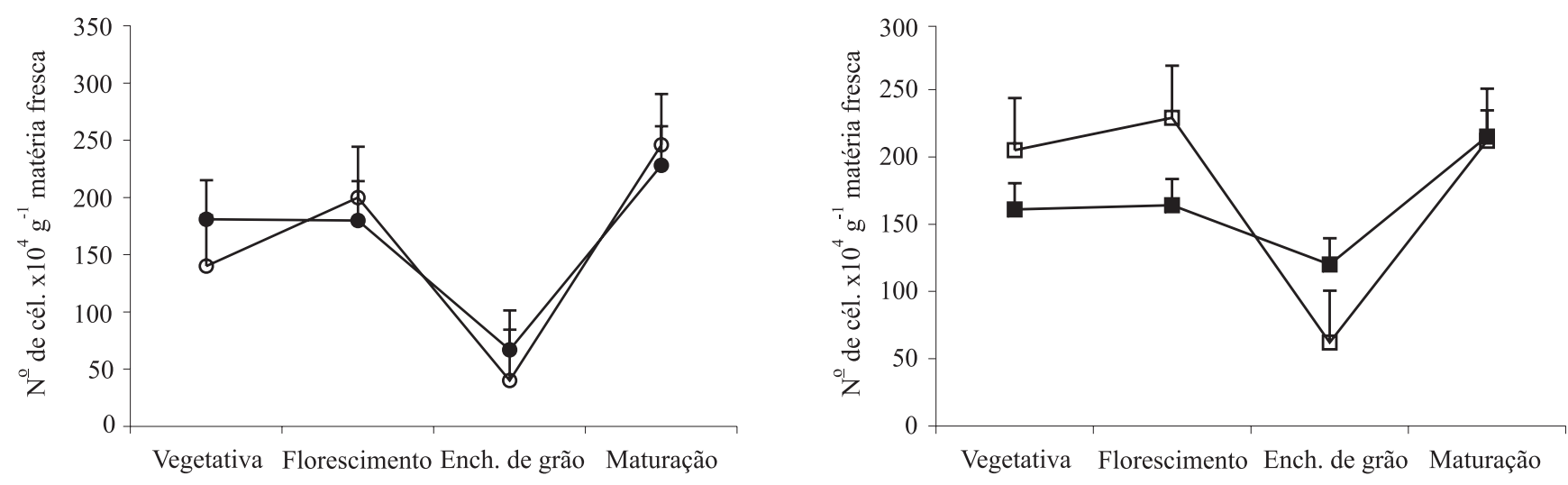

Experimento 2
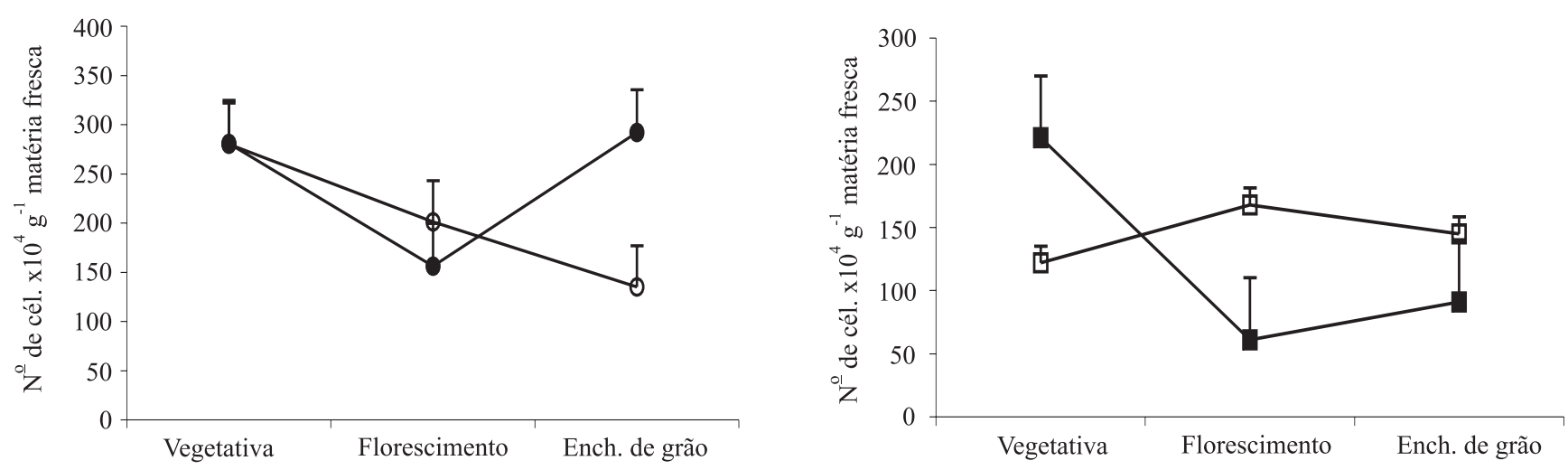

Figura 1. Número mais provável de bactérias diazotróficas endofíticas, cultivadas em meio JNFb, nas variedades de arroz IR 42-GO (O), IR 42-RJ ( ( ), IAC 4440-GO ( $\square$ ), IAC 4440-RJ ( $\square$ ), em quatro estágios de desenvolvimento. As barras representam o erro-padrão da média, obtido a partir dos valores das quatro épocas de coletas. Valores médios de quatro repetições. 

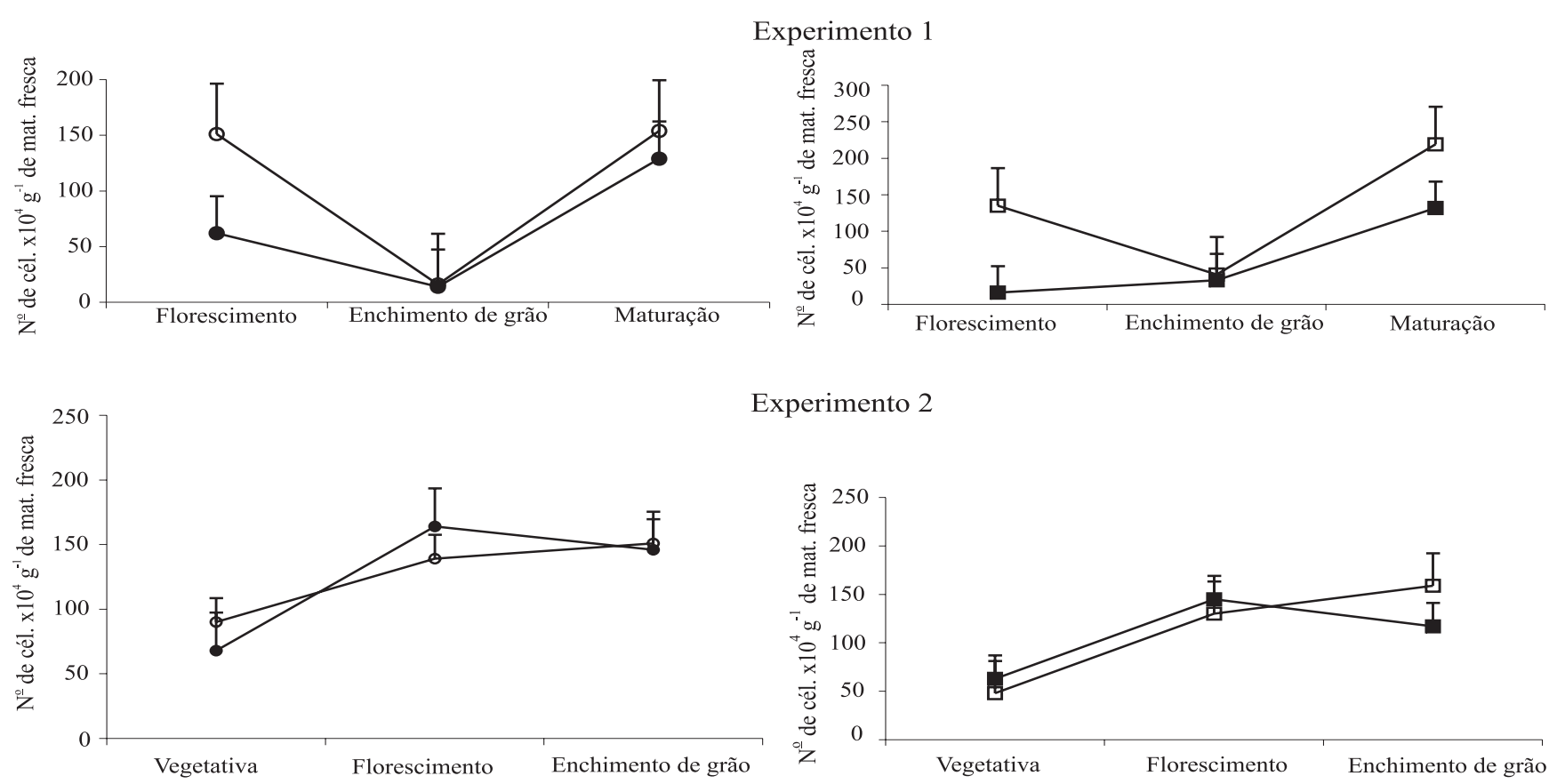

Experimento 2

Figura 2. Número mais provável de bactérias diazotróficas endofíticas, cultivadas em meio JMV, nas variedades de arroz IR 42-GO ( ○), IR 42-RJ ( ○), IAC 4440-GO ( $\square$ ), IAC 4440-RJ ( $\square$ ), em quatro estágios de desenvolvimento, em dois tipos de solo. As barras representam o erro-padrão da média, obtido a partir dos valores das quatro épocas de coletas. Valores médios de quatro repetições.

Tabela 1. Porcentagem e número de isolados obtidos a partir de amostra de raiz lavada, raiz esterilizada superficialmente, parte aérea e semente, das variedades de arroz IR 42 e IAC 4440, caracterizados quanto à sua morfologia, provenientes de dois tipos de solos, cultivados com arroz em dois Estados: Goiás (GO) e Rio de Janeiro (RJ), utilizando-se meio de cultivo semisólido sem adição de nitrogênio.

\begin{tabular}{lcc}
\hline Parte da planta & \multicolumn{2}{c}{ Porcentagem de isolados } \\
\cline { 2 - 3 } & Experimento 1 & Experimento 2 \\
\hline Raiz lavada & 45 & 47 \\
Raiz esterilizada & 30 & 29 \\
Parte aérea & 24 & 24 \\
Semente & 1 & 0 \\
\hline Solo-RJ & --------- - Número ---------- \\
IR 42 & 50 & 43 \\
IAC 4440 & 66 & 28 \\
\hline Solo-GO & & \\
IR 42 & 78 & 58 \\
IAC 4440 & 67 & 36 \\
\hline Número total & 261 & 165 \\
\hline
\end{tabular}

das etapas de isolamento dos dois experimentos, o gênero Burkholderia mostrou-se mais representativo do que Herbaspirillum, para as duas variedades de arroz plantadas em ambos os solos (Tabela 2).
A caracterização morfológica dos isolados de Herbaspirillum revelou células vibrióides (bacilos curvados) e móveis, e o crescimento no meio de cultivo JNFb (com três vezes o teor do indicador azul de bromotimol) mostrou a presença de colônias pequenas do tipo circular, com centro azul-escuro, pelo acúmulo do indicador (22 isolados), semelhante ao descrito por Baldani et al. $(1986,1996)$.

Foram caracterizados 120 isolados como pertencentes ao gênero Burkholderia. Segundo Estrada de Los Santos et al. (2001), vários membros de Burkholderia são capazes de crescer em meio com ácido azelaico como única fonte de carbono, e tendo a L-citrulina como única fonte de $\mathrm{N}$. A única exceção foi a espécie B. cepacia, que usa triptamina. Foram selecionados representantes de cada grupo para as caracterizações adicionais, no total de 40 isolados, sendo dez de cada variedade de arroz e tipo de solo. A análise comparativa dos dados obtidos por caracterização morfológica, das colônias dos isolados e estirpes M130 (Burkholderia sp.) e PPe8T (B. tropica), crescidas em meio JMV sólido, revelou a formação de grupos baseados nos parâmetros borda 
(filamentosa, inteira e denteada), elevação (pulvinada, umbonada, plana e convexa) e detalhes ópticos (aparência gomosa, brilhosa e fosca), refletindo grande variabilidade entre os isolados. Em geral, os isolados apresentaram características mais próximas das observadas para a estirpe tipo M130, também isolada de arroz, tendo diminuído as chances de ocorrência de B. tropica.

As análises de redução de acetileno (ARA) indicaram variação da atividade da nitrogenase entre os isola-

Tabela 2. Número de isolados total e número de isolados obtidos em dois gêneros avaliados, Herbaspirillum e Burkholderia, presentes nas diferentes partes da planta ${ }^{(1)}$.

\begin{tabular}{lcccccc}
\hline \multirow{2}{*}{$\begin{array}{l}\text { Parte da } \\
\text { planta }\end{array}$} & \multicolumn{3}{c}{ Número de isolados avaliados } & \multirow{2}{*}{ Total } \\
\cline { 2 - 3 } \cline { 2 - 5 } & \multicolumn{2}{c}{ Solo RJ } & & \multicolumn{2}{c}{ Solo GO } & \\
\cline { 2 - 3 } \cline { 5 - 6 } & IR 42 & IAC 4440 & & IR 42 & IAC 4440 & \\
\hline Raiz lavada & $5 \mathrm{H}+3 \mathrm{~B}$ & $5 \mathrm{H}+3 \mathrm{~B}$ & & $4 \mathrm{H}+3 \mathrm{~B}$ & $3 \mathrm{~B}$ & 26 \\
Raiz estéril & $2 \mathrm{H}+4 \mathrm{~B}$ & $4 \mathrm{~B}$ & $4 \mathrm{~B}$ & $2 \mathrm{H}+4 \mathrm{~B}$ & 20 \\
Parte aérea & $6 \mathrm{H}+3 \mathrm{~B}$ & $1 \mathrm{H}+3 \mathrm{~B}$ & $3 \mathrm{H}+3 \mathrm{~B}$ & $3 \mathrm{~B}$ & 22 \\
\hline Total & 23 & 16 & 17 & 12 & 68 \\
\hline
\end{tabular}

(1)Isolado caracterizado, a princípio, como pertencente ao gênero Herbaspirillum (H) ou Burkholderia (B). dos de Herbaspirillum e Burkholderia (Tabela 3). Foi observado, também, que a atividade máxima da nitrogenase tendeu a ser maior aos dois dias de crescimento, para as estirpes de Herbaspirillum, e aos seis dias para as estirpes de Burkholderia.

A análise do uso de diferentes fontes de carbono mostrou a formação de três grupos a $75 \%$ de similaridade (Figura 3). Um grupo apresentou comportamento semelhante às espécies Herbaspirillum frisingense e $H$. seropedicae e o outro à $H$. rubrisubalbicans. Neste último grupo, todos os isolados foram capazes de crescer em meio com meso-eritritol (ME). O terceiro grupo, formado por estirpes de $H$. seropedicae, ficou mais distante dos outros dois grupos e com $40 \%$ de similaridade. Em geral, os isolados comportaram-se como pertencentes a $H$. rubrisubalbicans e $H$. frisingense, quanto ao uso de diferentes fontes de carbono.

As fontes de carbono N-acetil-glucosamina (NA) e meso-eritritol (ME) são consideradas eficientes na diferenciação das espécies de Herbaspirillum (Olivares,

Tabela 3. Avaliação da atividade de redução de acetileno (ARA), dos isolados bacterianos e de estirpes tipo de Herbaspirillum e Burkholderia, depois do crescimento em meio JNFb e $\mathrm{JMV}^{(1)}$.

\begin{tabular}{|c|c|c|}
\hline \multicolumn{3}{|c|}{ Herbaspirillum } \\
\hline 48 horas de crescimento & 72 horas de crescimento & $\mathrm{ARA}$ (nmol de $\mathrm{C}_{2} \mathrm{H}_{4}$ por frasco) \\
\hline- & $23,26,151,154$ & 0 \\
\hline- & $10,11,14,24,156$ & $<3$ \\
\hline $\mathrm{M} 4^{\mathrm{T}}, \mathrm{Z} 67^{\mathrm{T}}, \mathrm{HCC} 103,2$ & $\mathrm{Z} 67^{\mathrm{T}}, \mathrm{HCC} 103, \mathrm{GSF} 30^{\mathrm{T}}, 12,13,19,22,153$ & $3-10$ \\
\hline GSF $30^{\mathrm{T}}, 3$ & $\mathrm{M}^{\mathrm{T}}, 1,3,18$ & $11-20$ \\
\hline $6,7,8,12$ & $2,6,7,21,152$ & $21-30$ \\
\hline $1,9,14,17,20,21,22$ & HRC $54,8,9,17,20$ & $31-40$ \\
\hline $10,13,18,24,153,154,156$ & $5,15,150,155$ & $41-60$ \\
\hline $15,19,23,26,149,151,152,155$ & 25,149 & $61-100$ \\
\hline $5,11,25,150$, HRC 54 & - & $101-148$ \\
\hline \multicolumn{3}{|c|}{ Burkholderia } \\
\hline Seis dias de crescimento & Oito dias de crescimento & \\
\hline- & 46,103 & 0 \\
\hline $\mathrm{PPe} 8^{\mathrm{T}}$ & - & $<10$ \\
\hline $\operatorname{TVV}^{\mathrm{T}}, 32,87$ & $\mathrm{PPe} 8^{\mathrm{T}}, 71$ & $10-20$ \\
\hline $\begin{array}{l}\mathrm{M} 130, \mathrm{KP}^{2} 3^{\mathrm{T}}, 45,55,75,92,109,112,114 \\
138\end{array}$ & $75,82,87,112$ & $21-40$ \\
\hline $\begin{array}{l}\text { M209, 39, 41, 46, 53, 57, 71, 72, 82, } 89 \\
\quad 100,117,128,132,133,141,142\end{array}$ & $\operatorname{TVV}^{2} 5^{\mathrm{T}}, 55,92,114,117,132,133,138,142$ & $41-60$ \\
\hline $35,36,77,97,103$ & $\begin{array}{l}\text { M130, M209, KP23 } 3^{\mathrm{T}}, 32,39,65,72,81,89,109,128, \\
\quad 139,141\end{array}$ & $61-80$ \\
\hline $63,64,65,120,139$ & $35,45,57,77,102$ & $81-100$ \\
\hline- & $41,97,120,121,129$ & $101-120$ \\
\hline 102,121 & $36,53,63$ & $121-140$ \\
\hline 81,129 & 64 & $>150$ \\
\hline
\end{tabular}

${ }^{(1)}$ Estirpes tipo utilizadas: M4T e HCC103 - H. rubrisubalbicans; Z67T e HRC54 - H. seropedicae; GSF30T - H. frisingense; PPe8T - B. tropica; TVV75T - B. vietnamiensis; e KP23T, M130, M209 - B. kururiensis. 
1997). Neste trabalho, observou-se a presença de dez isolados com comportamento semelhante ao de

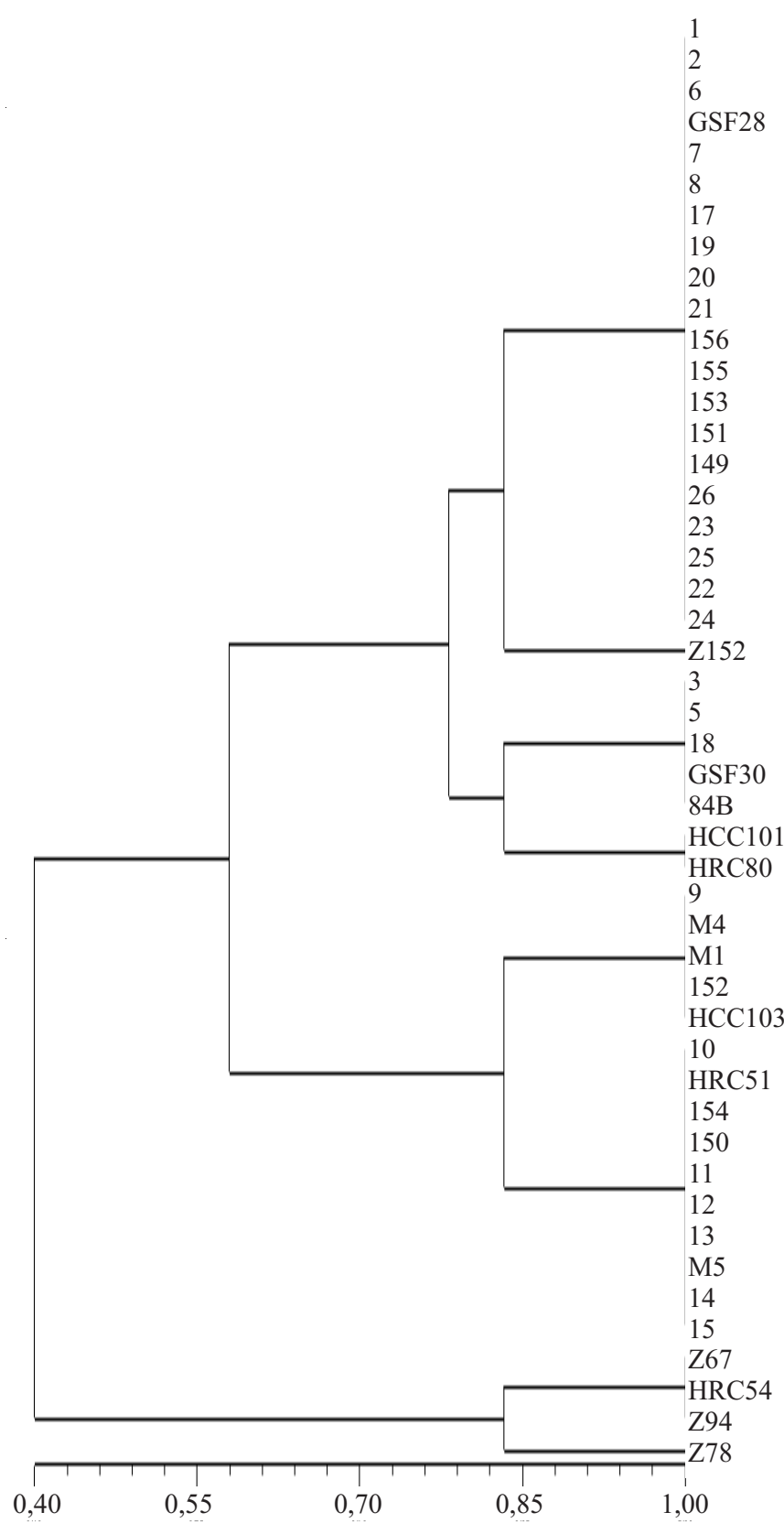

Figura 3. Dendrograma de similaridade gerado pelo método UPGMA e pelo índice SM, a partir da utilização de fontes de carbono de 32 isolados de Herbaspirillum, provenientes de diferentes partes das variedades de arroz crescidas nos dois tipos de solos, e de estirpes padrões de $H$. seropedicae (Z67T, Z78, Z152, Z94, HRC54, HCC101 e HRC80), H. rubrisubalbicans (M1, M4T, M5, HCC103, HRC51) e H. frisingense (GSF30T, GSF28 e 84BT).
H. rubrisubalbicans, ou seja, capazes de usar ME. $H$. seropedicae e $H$. frisingense têm a capacidade de usar NA, porém a última espécie difere de $H$. seropedicae, por não crescer em mio-inositol e L-ramnose (Kirchhof et al., 2001). Além disso, esses dez isolados de Herbaspirillum, assim como os demais, não foram capazes de usar MI, com adição ou sem adição de N. Este comportamento também foi observado para $H$. frisingense (Kirchhof et al., 2001) e H. rubrisubalbicans (Olivares, 1997). Entretanto, este último autor observou que cerca de $57 \%$ dos representantes de $H$. seropedicae foram capazes de crescer nessa fonte sem N. Este tipo de comportamento também foi evidenciado para os representantes de $H$. seropedicae. Diferentemente dos isolados de Herbaspirillum de arroz e das estirpes tipo das três espécies usadas como padrão, todas as estirpes de $H$. seropedicae cresceram em meio com mio-inositol com a adição de N. Nenhum dos dez isolados foi capaz de utilizar ácido adípico, sob condições de fixação biológica de nitrogênio. Porém, na presença de N, a maioria dos isolados utilizou este ácido. Somente algumas estirpes de $H$. rubrisubalbicans e $H$. frisingense puderam usar ácido adípico com N. Elbeltagy et al. (2001) também observaram que alguns isolados de Herbaspirillum, obtidos de arroz selvagem, foram capazes de usar ácido adípico sem $\mathrm{N}$, diferindo assim dos representantes das três espécies.

Em relação ao gênero Burkholderia, cerca de 20\% dos 95 compostos de carbono, que constituem o sistema Biolog, foram usados por todos os isolados e pelas estirpes tipo de Burkholderia. Os dendrogramas revelaram que, de modo geral, uma parte dos isolados se comportou, principalmente, como a estirpe tipo de B. vietnamiensis (TVV75), e outra parte como a estirpe tipo de B. kururiensis (KP 23), em relação ao uso de fontes de carbono (Figuras 4 e 5). Foram formados três grupos entre os isolados, com $80 \%$ de similaridade. A maioria dos isolados que se comportaram como B. vietnamiensis estão distantes, em aproximadamente $25 \%$, dos isolados com comportamento mais similares aos de B. kururiensis. Porém, observou-se que o último grupo mostrou um com- 
portamento mais próximo ao de B. tropica do que ao de $B$. vietnamiensis.

Nas duas variedades de arroz, cultivadas nos dois solos, foi possível observar a presença de isolados agrupados com B. kururiensis e com B. vietnamiensis. No entanto, não foi possível detectar influência do solo ou da variedade sobre os agrupamentos (Figuras 4 e 5). Ou seja, os dois grupos de isolados de Burkholderia, com comportamentos nutricionais distintos, estão distribuídos em diferentes regiões geográficas, visualizados pala origem dos solos utilizados. De acordo com Barraquio et al. (1997) e Stoltzfus et al. (1997), apesar da grande diversidade de bactérias endofíticas detecta- da em arroz, apenas uma pequena parcela das bactérias totais são diazotróficas. Não foi observado nenhum efeito seletivo do solo ou da variedade, sobre os representantes das espécies de Burkholderia, já que estas puderam ser isoladas de todos as variedades de arroz, plantadas em ambos os solos. Um efeito seletivo do solo do Rio de Janeiro foi notado sobre representantes de Herbaspirillum, capazes de crescer em meso-eritritol, que formaram um grupo homogêneo durante as análises de similaridade. Contudo, o baixo número de isolados de Herbaspirillum, obtidos por variedade, pode ser um fator que limitou a deteç̧ão de possíveis efeitos seletivos da planta sobre a população.
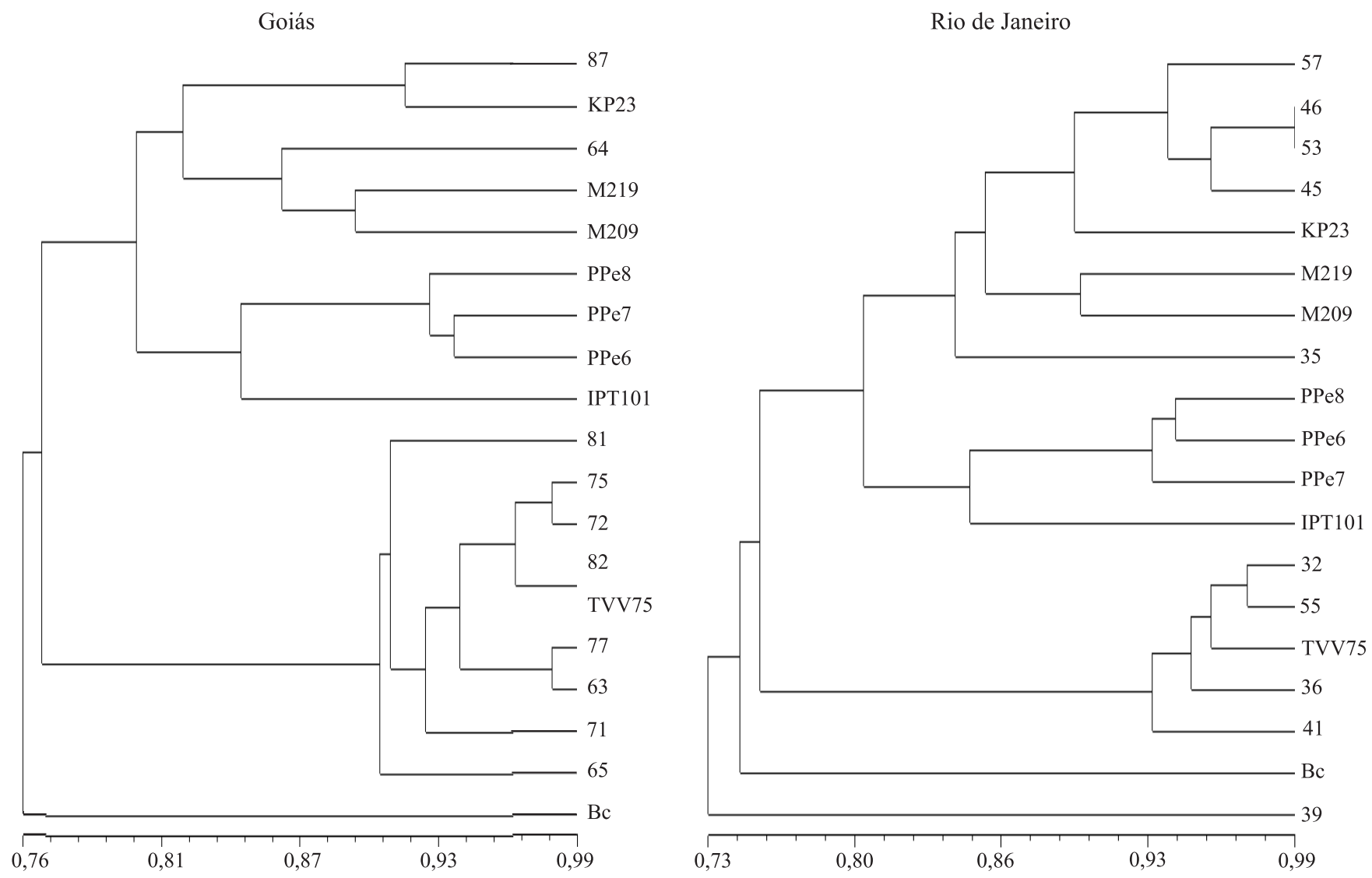

Figura 4. Dendrograma do uso de fontes de carbono, pelo sistema Biolog, dos isolados de Burkholderia obtidos da variedade de arroz IR 42, cultivada em solo proveniente de Goiás e Rio de Janeiro. Estirpes tipo utilizadas: PPe8T , PPe7, PPe 6 - B. tropica; TVV75 $^{\mathrm{T}}$ - B. vietnamiensis; KP23 ${ }^{\mathrm{T}}$, M209, M219 - B. kururiensis; e IPT101 - B. sacharii. 

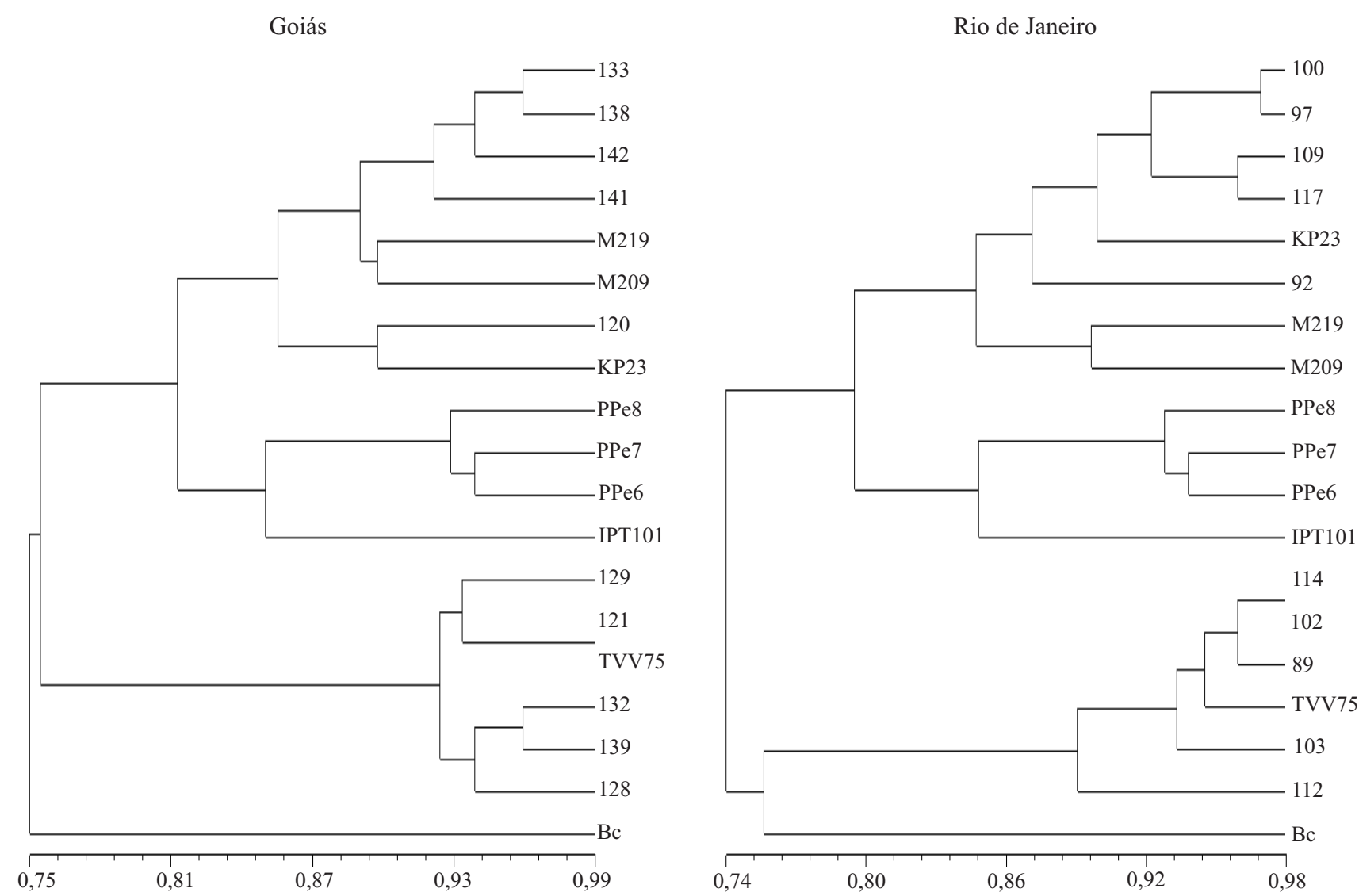

Figura 5. Dendrograma do uso de fontes de carbono, pelo sistema Biolog, dos isolados de Burkholderia obtidos da variedade IAC 4440, cultivada em solo proveniente de Goiás e Rio de Janeiro. Estirpes tipo utilizadas: PPe8T, PPe7, PPe 6 - B. tropica; TVV75T - B. vietnamiensis; KP23T, M209, M219 - B. kururiensis; e IPT101 - B. sacharii.

\section{Conclusões}

1. As populações de bactérias diazotróficas oscilam durante o desenvolvimento das variedades de arroz, nos dois tipos de solo.

2. O número de bactérias diazotróficas endofíticas, isoladas das duas variedades de arroz, do gênero Burkholderia é maior do que do gênero Herbaspirillum.

3. Não é possível detectar efeito de variedade ou de solo sobre os isolados de Herbaspirillum e de Burkholderia, exceto sobre os isolados capazes de crescer em meso-eritritol, como única fonte de carbono, e obtidos no solo do Rio de Janeiro.

4. Há diversidade das estirpes isoladas, em relação às estirpes padrões de espécies já descritas, o que sugere a presença de novos grupos, tanto de Burkholderia como de Herbaspirillum.

\section{Agradecimentos}

À Capes e ao CNPq, pelas bolsas concedidas; ao Pronex II/CNPq, pelo apoio financeiro.

\section{Referências}

AZEVEDO, M.S. Influência do solo e da planta hospedeira sobre a diversidade gênica de isolados de Azospirillum amazonense associados às raízes de arroz, milho e sorgo. 1998. 110p. Dissertação (Mestrado) - Universidade Federal Rural do Rio de Janeiro, Seropédica.

BALDANI, J.I.; BALDANI, V.L.D.; SELDIN, L.; DÖBEREINER, J. Characterization of Herbaspirillum seropedicae gen. nov., sp. nov., a root-associated nitrogen-fixing bacterium. International Journal of Systematic Bacteriology, v.36, p.86-93, 1986.

BALDANI, J.I.; CARUSO, L.; BALDANI, V.L.D.; GOI, S.R.; DÖBEREINER, J. Recent advances in BNF with non-legume plants. Soil Biology and Biochemistry, v.29, p.911-922, 1997. 
BALDANI, J.I.; POT, B.; KIRCHHOF, G.; FALSEN, E.; BALDANI, V.L.D.; OLIVARES, F.L.; HOSTE, B.; KERSTERS, K.; HARTMANN, A.; GILLIS, M.; DÖBEREINER, J. Emended description of Herbaspirillum; inclusion of [Pseudomonas] rubrisubalbicans, a milk plant pathogen, as Herbaspirillum rubrisubalbicans comb. nov.; and classification of a group of clinical isolates (EF group 1) as Herbaspirillum species 3. International Journal of Systematic Bacteriology, v.46, p.802-810, 1996.

BALDANI, V.L.D. Efeito da inoculação de Herbaspirillum spp. no processo de colonização e infecção de plantas de arroz e ocorrência e caracterização parcial de uma nova bactéria diazotrófica. 1996. 262p. Dissertação (Doutorado) - Universidade Federal Rural do Rio de Janeiro, Seropédica.

BALDANI, V.L.D.; BALDANI, J.I.; DÖBEREINER, J. Inoculation of rice plants with the endophytic diazotrophs Herbaspirillum seropedicae and Burkholderia spp. Biology and Fertility of Soils, v.30, p.485-491, 2000.

BARRAQUIO, W.L.; REVILLA, L.; LADHA, J.K. Isolation of endophytic diazotrophic bacteria from wetland rice. Plant and Soil, v.194, p.15-24, 1997.

BIOLOG. MicroLog system: release 4.0, user's guide. Hayward, USA, 1999. 109p.

CAMPOS, D.V.B. Identificação de genótipos de arroz irrigado com potencial para fixação biológica de nitrogênio. 1999. 94p. Dissertação (Mestrado) - Universidade Federal Rural do Rio de Janeiro, Seropédica.

DÖBEREINER, J.; BALDANI, V.L.D.; BALDANI, J.I. Como isolar e identificar bactérias diazotróficas de plantas não-leguminosas. Brasília: Embrapa-SPI; Seropédica: Embrapa-Cnpab, 1995. 60p.

ELBELTAGY, A.; NISHIOKA, K.; SATO, T.; SUZUKI, H.; YE, B.; HAMADA, T.; ISAWA, T.; MITSUI, H.; MINAMISAWA, K. Endophytic colonization and in planta nitrogen fixation by a Herbaspirillum sp. isolated from wild rice species. Applied and Environmental Microbiology, v.67, p.5285-5293, 2001.
ENGERLHARD, M.; HUREK, T.; REINHOLD HUREK, B. Preferential occurrence of diazotrophic endophytes, Azoarcus spp., in wild rice species and land races of Oryza sativa in comparison with modern races. Environmental Microbiology, v.2, p.131-141, 2000.

ESTRADA DE LOS SANTOS, P.; BUSTILLOS-CRISTALES, R.; CABALLERO-MELLADO, J. Burkholderia, a genus rich in plantassociated nitrogen fixers with wide environmental and geographic distribution. Applied and Environmental Microbiology, v.67, p.2790-2798, 2001.

KIRCHHOF, G.; ECKERT, B.; STOFFELS, M.; BALDANI, J.I.; REIS, V.M.; HARTMANN, A. Herbaspirillum frisingense sp. nov., a new nitrogen-fixing bacterial species that occurs in $\mathrm{C}_{4}$-fibre plants. International Journal of Systematic and Evolutionary Microbiology, v.51, p.157-168, 2001.

LADHA, J.K.; TIROL-PADRE, A.; PUNZALAN, G.C.; WATANABE, I. Nitrogen-fixing $\left(\mathrm{C}_{2} \mathrm{H}_{2}\right.$-reducing $)$ activity and plant growth characters of 16 wetland rice varieties. Soil Science and Plant Nutrition, v.33, p.187-200, 1987.

OLIVARES, F.L. Taxonomia, ecologia e mecanismos envolvidos na infeç̧ão e colonização de plantas de cana de açúcar (Saccharum sp. híbrido) por bactérias diazotróficas endofíticas do gênero Herbaspirillum. 1997. 344p. Tese (Doutorado) Universidade Federal Rural do Rio de Janeiro, Seropédica.

ROHLF, F.J. NTSYSpc: numerical taxonomy and multivariate analysis system. New York: Setauket, 1993. 191p.

STOLTZFUS, J.R.; SO, R.; MALARVITHI, P.P.; LADHA, J.K.; BRUIJN, F.J. de. Isolation of endophytic bacteria from rice and assessment of their potential for supplying rice with biologically fixed nitrogen. Plant and Soil, v.194, p.25-36, 1997.

UEDA, T.; SUGA, Y.; YAHIRO, N.; MATSUGUCHI, T. Remarkable $\mathrm{N}_{2}$-fixing bacterial diversity detected in rice roots by molecular evolutionary analysis of nifH gene sequence. Journal of Bacteriology, v.177, p.1414-1417, 1995.

Recebido em 15 de dezembro de 2004 e aprovado em 8 de julho de 2005 